\title{
PLOSIVE FEATURES OF PRONUNCIATION WITH DEAF CHILDREN
}

UDC 81'342.2-056.263-057.874(049.5)

\author{
Jasmina Kovačević1 \\ Admira Beha \\ Faculty of Special Education and Rehabilitation, University of Beograd \\ Faculty for education and rehabilitation, University of Tuzla
}

Received: 08.06.2011

Accepted: 14.07.2011

\begin{abstract}
This research shows the results of efficiency in articulating plosives and the discrimination of plosive couples with deaf children in the elementary school. For the purpose of this research we have used: a global articulation test and a test to distinguish phonemes. The study was performed on 24 deaf students, and the results indicate the existence of differences in the discrimination of plosive pairs between students of younger and older age, but also the lack of difference in the articulation of plosives between the two groups of participants.
\end{abstract}

Key words: plosives, plosive couples, deaf students

\section{INTRODUCTION}

The most obvious consequence of hearing impairment is partially developed or undeveloped speech. As a support for the construction of oral voice, deaf children are involved in an intensive rehabilitation treatment. Nevertheless, according to the research of Branona (1966), intelligibility of the deaf is very bad, and the interlocutor understands only one out of five spoken words.

The largest number of deaf children has a hard time adopting the rules of standard speech of the hearing environment, and the most common articulation errors that occur are: omission, substitution and distortion of the voices.

According to Osberger (1986) some articulators such as lips, even though they are very visible, at the same time, they are very limited. They allow fewer errors, than other speech organs.

1 Correspodence to:

Jasmina Kovačević, PhD, Faculty of Special Education and Rehabilitation, University of Beograd

Viskog Stevana 2, 11000 Beograd, Srbija

Phone: +381 112183036

E-mail: dekan@fasper.bg.ac.rs 
Hantington, Haris and Sholes (1968) states that deaf people set the articulator properly, especially for the voices that are well perceived visually, but have difficulties when it comes to the coordination of movement of the articulators.

Voices that deaf people pronounce relatively well belong to the group of plosives. These are the voices that are controlled by extra auditive modalities. After the learning of the vowels, rehabilitation program continues with the learning of the plosives, especially because of their way of articulation.

Although deaf children with a programmed multiple years of rehabilitation tend to adopt and discriminate plosives, difficulties often arise. Smith (1975) points out that deaf child most often will adopt the proper plosive, but Monsen (1976) states that the largest number of deaf people fails to distinguish the sound from the soundless voices. The most common substitutions occur in pairs: $P$ and $\mathrm{B}, \mathrm{T}$ and $\mathrm{D}$, and $\mathrm{K} \& \mathrm{G}$.

The aim of this paper was to determine the efficiency of plosive articulation and discrimination of plosive pairs, compared to their initial position in the words of deaf students. It was assumed that there is no difference in efficiency of plosive pronunciation between the two groups, and also that there was a statistically significant difference in discrimination plosive pairs between the two groups of participants.

\section{METODS}

\section{Sampling}

Testing was conducted on a sample of 24 hearing impaired students who attend classes from second to seventh grade at the Centre for education, training and rehabilitation of hearing and speech in Tuzla. The first subsample consisted of the younger group, ages 8.5 to 12 years, and another older group, ages from 12 to 16.5 years. The participant selection was done based on the data obtained from the individual files of the internal data base of the Center.

\section{Variables}

For this study we analyzed the following variables: efficiency pronunciation of plosives in the initial position, discrimination of phonemes in words containing plosives in initial position.

\section{Method of data processing}

The data from this study was analyzed using method of parametric statistics. By using descriptive analysis, we calculated basic statistic indicators, and based on those results, statistical analysis was done, and differences between the groups were tested with t- distribution.

Based on the statistic indicators we ranked the average values, which represent the scientific classification sizes of the applied problem parameters.

\section{RESULTS AND DISCUSSION}

For this study to determine the effectiveness of pronunciation of plosives we used a global pronunciation test or "seven members scale" and a test for distinguishing phonemes. This test was used to verify the effectiveness of word pronunciation of plosives in initial position. We also used additional words from the test, for testing to distinguish phonemes, which contained plosives in initial position. The quality of pronunciation of each plosive was quantified by numerical values from 1 to 7 .

According to the results of $t$ test, the comparing of the pronunciation of the same voices between the two age groups showed no statistical significant difference in the efficiency of pronouncing the plosives voices.

Table 1. Discrimination of the plosive pairs

\begin{tabular}{ccc}
\hline Plosive & $\begin{array}{c}\text { Average grade of the } \\
\text { younger participants }\end{array}$ & $\begin{array}{c}\text { Average grade of the older } \\
\text { participants }\end{array}$ \\
\hline P & 4,16 & 4,16 \\
B & 4,44 & 4,28 \\
T & 4,33 & 4,30 \\
D & 5,00 & 5,25 \\
K & 4,89 & 5,50 \\
G & 5,97 & 6,00
\end{tabular}


By looking at the Table 1, we can conclude that the participants in the both groups got the lowest results when discriminating the voices $P$ and B. These results can be attributed to the fact, that deaf subjects rely in the communication on reading speech from the face and lips, which leads to a substitution of the voices similar to the place of formation such as P and B. Examining the possibilities of discriminating certain plosive pairs, we concluded that the older participants showed better results.

Both groups of participants showed good results in diffracting these plosive pairs: P-K, K-T and G-P. On the other hand, plosive pairs that older subjects have harder time differentiating are: P-B, K-G and T-D, while the subjects of the other group have harder time differentiating plosive pairs T-D, $\mathrm{K}-\mathrm{G}$ and K-D.

According to the $\mathrm{t}$ test results, with $0.5 \%$ risk of the hypothesis, this showed that there was no statistically significant difference in efficiency between the pronunciations of plosives in the two groups. The alternative hypothesis of the existence of statistically significant differences in discrimination of plosive pairs in subjects of the younger and older age groups is accepted. Participants of the older age group showed better results in discrimination of voices, on the scale of 1 to 7 .

\section{CONCLUSION}

Test results confirm previous findings on the effectiveness of the adoption and discrimination plosive pairs in the world. Although they are well visually perceived, deaf children have difficulties in discriminating the plosives by their sound and their place of formation. Practically on the basis of these results, the programming rehabilitation of the deaf on the correct discrimination of plosives can be done.

\section{REFERENCES}

Brenon. Jr., J.B. (1966). The speech production and spoken language of the deaf. Language and Speech.

Huntington. D., Haris.K.S., \& Sholes G. (1968). An electromyographic study of consonan articulations in hearing-imapried and normal speakers. Journal of Speech and Hearing Research.

Monsen. R.B. (1976). The production of English stop consonants in the speech of deaf children. Journal of Phonetics. Osberger, J. M., (1986). Lanuage and learning skills of hearing-imparied student. ASHA Monographs, 23, Rockville, Mary land.

Smith, A. (1975). Residual hearing and speech production in deaf. Journal of Speech and Hearing Research. 